\title{
Review Article \\ Potential Developmental and Reproductive Impacts of Triclocarban: A Scoping Review
}

\author{
Johanna R. Rochester, ${ }^{1}$ Ashley L. Bolden, ${ }^{1}$ Katherine E. Pelch, ${ }^{1}$ and Carol F. Kwiatkowski ${ }^{1,2}$ \\ ${ }^{1}$ The Endocrine Disruption Exchange (TEDX), Eckert, CO, USA \\ ${ }^{2}$ Department of Integrative Physiology, University of Colorado, Boulder, CO, USA \\ Correspondence should be addressed to Johanna R. Rochester; johanna.rochester@gmail.com
}

Received 6 September 2017; Accepted 31 October 2017; Published 23 November 2017

Academic Editor: Jone Stanley

Copyright ( 2017 Johanna R. Rochester et al. This is an open access article distributed under the Creative Commons Attribution License, which permits unrestricted use, distribution, and reproduction in any medium, provided the original work is properly cited.

\begin{abstract}
Triclocarban (TCC) is an antimicrobial agent used in personal care products. Although frequently studied with another antimicrobial, triclosan, it is not as well researched, and there are very few reviews of the biological activity of TCC. TCC has been shown to be a possible endocrine disruptor, acting by enhancing the activity of endogenous hormones. TCC has been banned in the US for certain applications; however, many human populations, in and outside the US, exhibit exposure to TCC. Because of the concern of the health effects of TCC, we conducted a scoping review in order to map the current body of literature on the endocrine, reproductive, and developmental effects of TCC. The aim of this scoping review was to identify possible endpoints for future systematic review and to make recommendations for future research. A search of the literature until August 2017 yielded 32 relevant studies in humans, rodents, fish, invertebrates, and in vitro. Based on the robustness of the literature in all three evidence streams (human, animal, and in vitro), we identified three endpoints for possible systematic review: estrogenic activity, androgenic activity, and offspring growth. In this review, we describe the body of evidence and make recommendations for future research.
\end{abstract}

\section{Introduction}

Triclocarban (TCC) is an antimicrobial agent primarily used in bar soaps, plastics (including toys, tableware, and utensils), cleansing lotions, and wipes [1,2]. Although TCC and triclosan are frequently discussed and studied in tandem, TCC is a carbanilide (the two aromatic rings are linked by urea), whereas triclosan is a diphenyl ether (with oxygen linking the rings) [3]. Because of this, they may have different biological activity $[3,4]$.

Due to concerns regarding the effects of TCC on human health, exposure has been assessed in human populations residing in China, Europe, Canada, and the US. In the large-scale US biomonitoring study NHANES (2013-2014), TCC was detected in human urine in $\sim 36 \%$ of individuals with concentrations up to $68 \mu \mathrm{g} / \mathrm{L}$. Sex (male), age (20+ years), race (non-Hispanic black), and increased body surface area were significantly associated with higher concentrations of TCC [5]. In another US study of pregnant women in
Brooklyn, TCC had a detection frequency of $86.7 \%$ and its metabolites $2^{\prime}$-OH-TCC, $3^{\prime}$-OH-TCC, and $3^{\prime}$-Cl-TCC were found in $27.1 \%, 16.6 \%$, and $12.7 \%$, respectively [6]. In a study done by the US Centers for Disease Control (CDC), TCC was detected in $35 \%$ of urine samples tested, and the metabolites $2^{\prime}$-OH-TCC and $3^{\prime}$-OH-TCC were detected in $16 \%$ and $14.5 \%$ of urine samples, respectively. In the same study, serum TCC was detected in $44 \%$ of samples (although the metabolites were not detected above the limit of detection (LOD)). TCC was again detected more frequently in males than in females in the CDC study [7].

Interestingly, a Canadian biomonitoring study (the Canadian Health Measures Survey [CHMS]) found that only $4 \%$ of the population had detectable urinary TCC [8]. In another Canadian study, TCC was detected in less than $4 \%$ of infant urine and meconium samples and was not detected in infant formula or breast milk [9]. The authors attributed their findings, corroborated by the more recent study, to limited use of the chemical in Canada [9]. Similarly, a study 
done in Greece found a detection rate of $4 \%$ in urine with a mean level of $0.6 \mathrm{ng} / \mathrm{mL}$ (LDQ-1.9 ng/mL) [10]. In a 2013 Danish study done in mother-child pairs, TCC was detected at levels over the LOD in $25 \%$ of mothers and $28 \%$ of children, with mean TCC levels of 0.08 (LOD-1.3) and 0.07 (LOD1.0) [11]. In a 2014 study of Danish pregnant women, TCC was found in $54 \%$ of samples tested [12]. When measured in children/adolescents, young men, and pregnant women, the compound was detected in $54 \%, 17 \%$, and $18 \%$ of samples, respectively [13]. A study in a Chinese population found TCC in almost all (99-100\%) of the urine samples tested, with high concentrations detected in the toenails and fingernails of the subjects [14]. Clearly, exposure to TCC varies by populations, with location, sex, age, and race/ethnicity possibly playing a role. This is likely due to the variable use of the chemical in consumer products by countries and individuals.

There has been very little research on the indirect exposure of offspring during development. However, in two studies by Enright et al., TCC has been shown to transfer to the fetus via maternal exposure in both human placental in vitro and rodent in vivo models $[15,16]$. In the in vivo models, TCC was found in maternal and fetal placental tissue, as well as in the fetus. TCC also transfers to offspring during lactation in exposed mothers $[15,16]$.

TCC is an environmental contaminant (it was one of the most commonly detected organic wastewater and surface water contaminants in the US in 2011), with concentrations as high as $6.75 \mu \mathrm{g} / \mathrm{L}$. It is toxic to aquatic organisms (perhaps more so than triclosan), with an LC50 (i.e., the concentration of $50 \%$ lethality) as low as $3.1 \mu \mathrm{g} / \mathrm{L}$ in certain organisms [17]. It has been shown to bioaccumulate in aquatic organisms, such as snails $[17,18]$. In fish, TCC also bioaccumulates. However, TCC has been shown to be rapidly metabolized and eliminated after absorption in fish, facilitated by the in vivo conversion of TCC to its sulfate and glucuronic acid conjugate metabolites (i.e., $2^{\prime}$-O-Gluc-TCC, $2^{\prime}$-O-SO3TCC, $2^{\prime}$-OH-TCC, $3^{\prime}$-OH-TCC, and 6-OH-TCC). Thus, the bioaccumulation in fish is less than would be predicted by the n-octanol/water partition coefficient of TCC [19].

The route of metabolism and the metabolites produced are similar in humans and other mammalian species [20-24]. In humans exposed orally to TCC, the urinary elimination half-life was about 20 hours [21]. With intravenous injection, the urinary elimination half-life was estimated to be 10 hours. In the same study, individuals were exposed to TCC through a whole body wash in the shower. The urinary elimination halflife in this case was 28 hours; however, the bulk of excretion was detected in the feces, which was detected 12-20 days after exposure [25]. The fact that some human populations had up to $100 \%$ detection indicates the ubiquitous exposure of TCC in certain groups [14].

Although TCC has been widely used for over 50 years, it was only recently that concerns were raised about its endocrine disruptive properties. In 2016, the FDA banned its use in over-the-counter hand and body washes [26]. This was due to the fact that manufactures were unable to show that TCC was safe for daily use or was any more effective than regular soap alone. However, TCC is still used in other countries (as evidenced by human exposure)
$[11,12,14]$ and the chemical is still approved in the US for all other personal care products, including deodorants, lotions, and toothpaste, as well as for medical and healthcare applications [26]. A 2007 study put forth the idea that TCC was a "new kind of endocrine disruptor" that augmented the action of endogenous hormones rather than directly activating hormone receptors [27]. More recently, TCC has been shown to disrupt the gut microbiome in animals [28] and humans [29], which, in turn, can have myriad effects on health [30]. Because of these potential endocrine-disruptive properties of TCC and the potential for TCC to be transferred to offspring during development, we conducted a scoping review to catalogue and map the literature-to-date on the endocrine, reproductive, and developmental effects of TCC.

\section{Methods}

2.1. Literature Search and Study Identification. A comprehensive literature search was performed to identify studies describing the endocrine, reproductive, and developmental effects of exposure to TCC. The search included all articles published for all years to August 2017. Electronic searches were performed in Web of Science, PubMed, and TOXLINE using the following search criteria: triclocarban OR trichlocarban OR triclocarbanum OR trilocarban OR (N-(4-chlorophenyl-N-(3,4-dichlorophenyl)) urea) OR (N(3,4-dichlorophenyl-N-(4-chlorophenyl) urea) OR (1- $\left(3^{\prime}, 4^{\prime}\right.$ Dichlorophenyl) -3- ( $4^{\prime}$-chlorophenyl)) urea) OR trichlorocarbanilide OR trichlorodiphenylurea OR 101-20-2. 101-20-2 is the Chemical Abstracts Services (CAS) Registry Number for triclocarban. For inclusion, the studies had to be original works, be in the English language, and assess endocrine, reproductive, or developmental effects of triclocarban exposure, including human, in vitro, and in vivo models. All titles and abstracts were screened for inclusion independently by two reviewers using the software DistillerSR ${ }^{\circledR}$ (Evidence Partners, Ottawa, Ontario, Canada). Conflicts or discrepancies were resolved by the two reviewers.

2.2. Data Extraction. Parameters collected during data extraction included author information, year of publication, summary of endpoint(s) evaluated, information about the model used (e.g., cell line and species), concentrations/doses tested, exposure duration, age at exposure, and route of exposure. The data extraction entries were inputted by one reviewer and then quality-checked by a second reviewer. Any discrepancies were resolved by discussion.

\section{Results}

Our searches for potentially relevant studies resulted in 1560 articles. A total of 32 studies ( 2 human, 19 in vivo animal, and 11 in vitro only) were identified as relevant and these studies underwent full review and data extraction. The summary statistics of the body of literature are presented in Table 1 . The majority of the research on this topic has been published in the years since 2010 , with over $90 \%$ of the literature published in the past 7 years. Studies were identified in all three categories: development, endocrine, and reproduction. Doses 
TABLE 1: Summary of the studies evaluating the endocrine, reproductive, and developmental effects of triclocarban.

\begin{tabular}{lc}
\hline & Number of studies (\%) \\
\hline Total number of studies & 32 \\
Publication date & $29(91)$ \\
$2010-2017$ & $2(6)$ \\
$2000-2009$ & $1(3)$ \\
$1969-1999$ & $18(56)$ \\
In vivo studies & $2(6)$ \\
Human & $13(41)$ \\
Animal & $2(6)$ \\
$\quad$ Mouse & $3(9)$ \\
$\quad$ Rat & $7(22)$ \\
Fish & $3(9)$ \\
Mollusk & $3(9)$ \\
Crustacean & $1(3)$ \\
Echinoderm & $1(3)$ \\
$\quad$ Rotifer & $14(44)$ \\
In vitro studies & \\
Age of exposure & $3(9)$ \\
Embryonic & $3(9)$ \\
Neonatal & $3(9)$ \\
Larval & $3(9)$ \\
Juvenile & $10(31)$ \\
Adult &
\end{tabular}

in aquatic studies ranged from $100 \mathrm{ng} / \mathrm{L}$ to $10000 \mu \mathrm{g} / \mathrm{L}$, with many studies in the range of the $6.75 \mu \mathrm{g} / \mathrm{L}$ found in US surface waters. The mammalian studies generally exposed animals to high doses, although a recent 2017 study used $100 \mathrm{nM}$, with the authors indicating that this was an "environmentally relevant concentration" [16].

3.1. Development. There were 11 studies identified with developmental endpoints, including two human studies. The human studies are presented in Table 2 and the animal studies in Table 3. The human studies assessed fetal malformations [31] and other birth parameters (gestational age at birth, birth weight, and body length/head size) [32]. Two studies in rodents examined birth and offspring weight $[16,33]$. Other studies in rotifers [34], crustaceans $[35,36]$, echinoderms [37], mollusks [38], and fish [37, 39, 40] measured endpoints in offspring such as lifespan/survival, size, malformations, and altered gene expression.

3.2. Reproduction/Endocrine. Thirteen studies assessed the reproductive/endocrine effects of TCC in vivo (Table 3). Four studies assessed effects in rodents including sex organ weights (males) [27, 41], reproduction and mammary gland disruption (females) [33], and activity of the constitutive androstane receptor (CAR) [42]. One of these studies assessed steroidal augmentation of TCC [27], while the other three looked at the effects of TCC alone. Other species studied were a crustacean [43], mollusks [44, 45], and fish [39-41, 46-49]. Endpoints included fecundity, spermatogenesis/oogenesis, endogenous steroid levels, masculinization, and steroidinduced gene/protein expression (including vitellogenin).

3.3. In Vitro/Steroid Activity. In systematic review frameworks, such as the Office of Health Assessment and Translation (OHAT) Systematic Review Framework, in vitro mechanistic evidence can be quantitatively used to support health hazard conclusions [50]. The in vitro studies are presented in Table 4. Fourteen studies assessed the steroidal activity of TCC, which may support the biological plausibility of the reproductive/endocrine effects of TCC in vivo [27, 41, 42, 51-61]. These studies measured steroid and steroid receptor activity, including estrogen, androgen, progesterone, thyroid, and glucocorticoid, as well as CAR activity. Table 5 shows the studies organized by the specific steroidal activity assessed. Some of these studies tested the possible steroid-enhancing activity of TCC, while others looked at the direct activities of TCC alone.

\section{Discussion}

Scoping reviews systematically map areas of research and can have several applications. They are employed during the first step of a systematic review in order to identify sources and types of available research to determine the feasibility/utility of carrying out a systematic review and to prioritize endpoints that can be evaluated through systematic review. They can also be used to help identify data gaps and direct future research. They have been used in the clinical sciences for many years [62-64] and have more recently been employed as tools in environmental health $[65,66]$. While scoping reviews are extremely useful for generating hypotheses for systematic review, they do not themselves answer research questions (e.g., whether or not a chemical is harmful to human or environmental health) [67-70]. In this scoping review, we aimed to identify and map the literature-to-date of the endocrine, developmental, and reproductive effects of TCC on organisms in order to identify endpoints for future systematic review and determine if additional research is needed in specific areas.

4.1. Possible Systematic Review Endpoints. Our recommendations for future systematic reviews are based on several variables. In particular, endpoints suitable for systematic review ideally have literature in all three "evidence streams" (human, animal, and in vitro), although literature in all streams is not required for final analyses. Meta-analysis, which usually requires at least three studies on a specific endpoint, is an optional component of systematic reviews, and is especially useful when there are "conflicting" results from studies. Meta-analyses are helpful for determining the degree of hazard, if any, which is posed to humans [50]. The characteristics of the recommended systematic review endpoints are presented in Table 6.

When examining reproductive/endocrine endpoints, there is sufficient literature on the estrogenic and/or androgenic effects of TCC in animals to undertake a systematic review, including three rodent studies and eight nonmammalian studies. Further, there are many in vitro studies 
TABLE 2: Human studies evaluating the developmental effects of triclocarban.

\begin{tabular}{|c|c|c|c|c|c|}
\hline Author & $\begin{array}{l}\text { Number } \\
\text { of } \\
\text { subjects }\end{array}$ & $\begin{array}{c}\text { Age of } \\
\text { subjects at } \\
\text { time of } \\
\text { exposure }\end{array}$ & $\begin{array}{c}\text { Concentration } \\
\text { detected }\end{array}$ & $\begin{array}{c}\text { Exposure } \\
\text { measurement }\end{array}$ & Summary \\
\hline $\begin{array}{l}\text { Geer et al., } \\
2017\end{array}$ & 185 & $\begin{array}{l}\text { Adult; } \\
\text { prenatal }\end{array}$ & $\begin{array}{c}0.13 \mu \mathrm{g} / \mathrm{L}(\mathrm{cbp}) \\
3.44 \mu \mathrm{g} / \mathrm{g} \\
\text { creatinine (urine) }\end{array}$ & $\begin{array}{l}\text { Maternal urine } \\
\text { and cord blood }\end{array}$ & $\begin{array}{l}\text { Cord blood plasma TCC was associated with decreased } \\
\text { gestational age at birth in an immigrant population in } \\
\text { Brooklyn, New York, in linear models adjusted for } \\
\text { demographic confounders. The TCC metabolite } 3^{\prime} \text {-Cl-TCC } \\
\text { in third-trimester maternal urine was associated with fewer } \\
\text { low birth weights. }\end{array}$ \\
\hline $\begin{array}{l}\text { Wei et al., } \\
2017\end{array}$ & 92 & $\begin{array}{l}\text { Adult; } \\
\text { prenatal }\end{array}$ & $\begin{array}{c}0.248 \mathrm{ng} / \mathrm{mL} \\
(\mathrm{ms}) ; 0.105 \mathrm{ng} / \mathrm{mL} \\
(\mathrm{cs})\end{array}$ & $\begin{array}{c}\text { Maternal } \\
\text { venous and } \\
\text { umbilical cord } \\
\text { blood }\end{array}$ & $\begin{array}{l}\text { TCC levels were determined in a case-control study of } \\
\text { mothers with abnormal births set in Beijing, China. Cases } \\
\text { had one or more fetal anomalies and controls had no } \\
\text { malformations. Levels of TCC in maternal sera were } \\
\text { correlated with levels in cord blood. There was no difference } \\
\text { in TCC in maternal sera or cord blood between cases and } \\
\text { controls. }\end{array}$ \\
\hline
\end{tabular}

ms: maternal serum; cs: cord serum; cbp: cord blood plasma.

that might support the biological plausibility of the estrogenic/androgenic action of TCC, as most of the in vitro studies assessed these endpoints (Table 5). Although there are no human studies assessing these endpoints, there are sufficient studies (5) to evaluate vitellogenin expression in a meta-analysis, if desired. Vitellogenin is an estrogenresponsive egg protein in egg-laying animals and, when found in males, indicates exposure to estrogenic chemicals [71]. Both the animal and in vitro literatures in this area have studies examining the direct effects of TCC as well as steroid augmentation effects. A review employing systematic methodologies, comparing these two types of effects, could shed light on the mechanisms of TCC activity.

There are fewer studies on specific developmental endpoints, and therefore the developmental effects of TCC may not yet be mature enough for conducting a systematic review. One possible endpoint to pursue, however, is offspring size (birthweight and lifetime weight). This endpoint is represented in 1 human study [32] and 6 animal studies ( 2 rodent and 4 nonmammalian) $[16,33,35,37,39,40]$. The fact that all three data streams are represented is a positive aspect for systematic review. There is also mechanistic evidence that could possibly be used to support the biological plausibility of TCC's effects on offspring growth, for example, TCC's effects on metabolic genes in vivo [16] and TCC activity on the thyroid receptor in vitro [55]. In all, however, there is little research on specific developmental endpoints.

4.2. Future Research. In order to protect human and wildlife health as quickly and efficiently as possible, further research of the effects of TCC should be prioritized. Overall, studies designed to be relevant to human health and risk assessment are needed, including identifying sensitive target tissues and functional assays, employing doses within the range of human exposure and using relevant models. Table 7 outlines the state of the current research and identifies data gaps with respect to model and endpoint. While mechanistic models seem to be well represented, human and mammalian models are less so.

There are also data gaps with respect to endpoint. One endpoint that appears to be particularly responsive to low exposures (i.e., comparable to those reported in humans) is increased weight in offspring following developmental exposure [16]. This should be further explored in developmental animal studies and prospective epidemiological studies that follow the growth of children. In vitro studies exploring possible mechanisms for these actions would add to the body of literature as well. In general, more human studies would be helpful in understanding the effects of TCC, as we only found two human studies documenting the effects of TCC exposure.

For endocrine/reproductive effects, the majority of the literature is in aquatic species. Endpoints in these papers, such as vitellogenin induction, appear to be sensitive to low doses of TCC. However, the current endocrine/reproductive literature in mammals is less robust, and the endpoints studied, such as reproductive organ weights, are not as sensitive. Further research in this area should include mammalian models, with endpoints that are responsive to low doses of chemicals, such as ovarian histology and mammary disruption.

Lastly, the finding that TCC acts as a "steroid augmenter" should be studied further. The ability of endocrine disruptors to enhance the activity of endogenous hormones has not been extensively explored. TCC (and triclosan) appears to act this way in vivo and in vitro, and this may be a unique characteristic of these chemicals. Further study of this mechanism (and inclusion of assays that identify this activity among more chemicals) could be informative to the broader field of endocrine disruption.

\section{Conclusions}

Our scoping review found that systematic review(s) of the effects of TCC on human health could be carried out using 


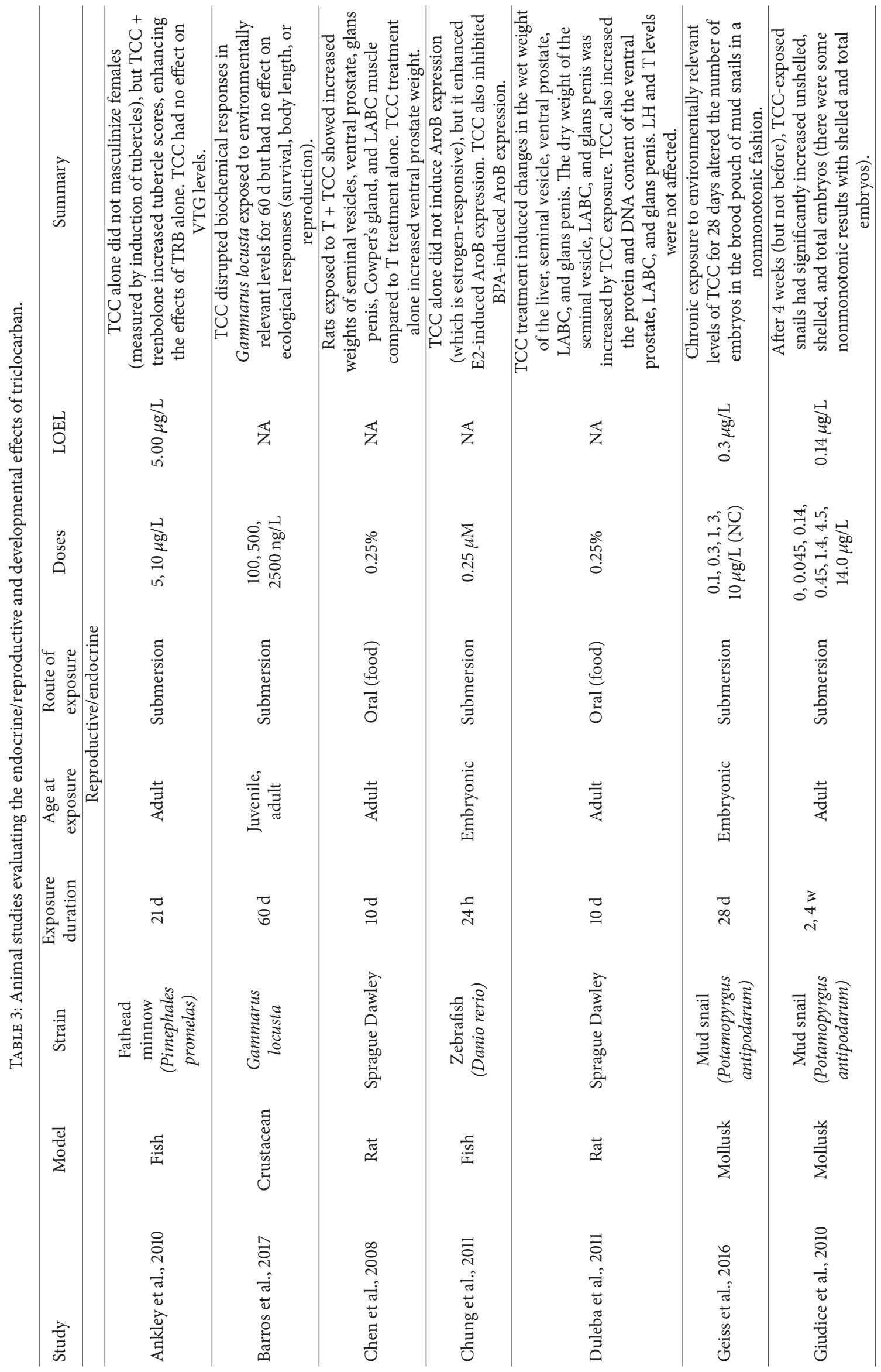




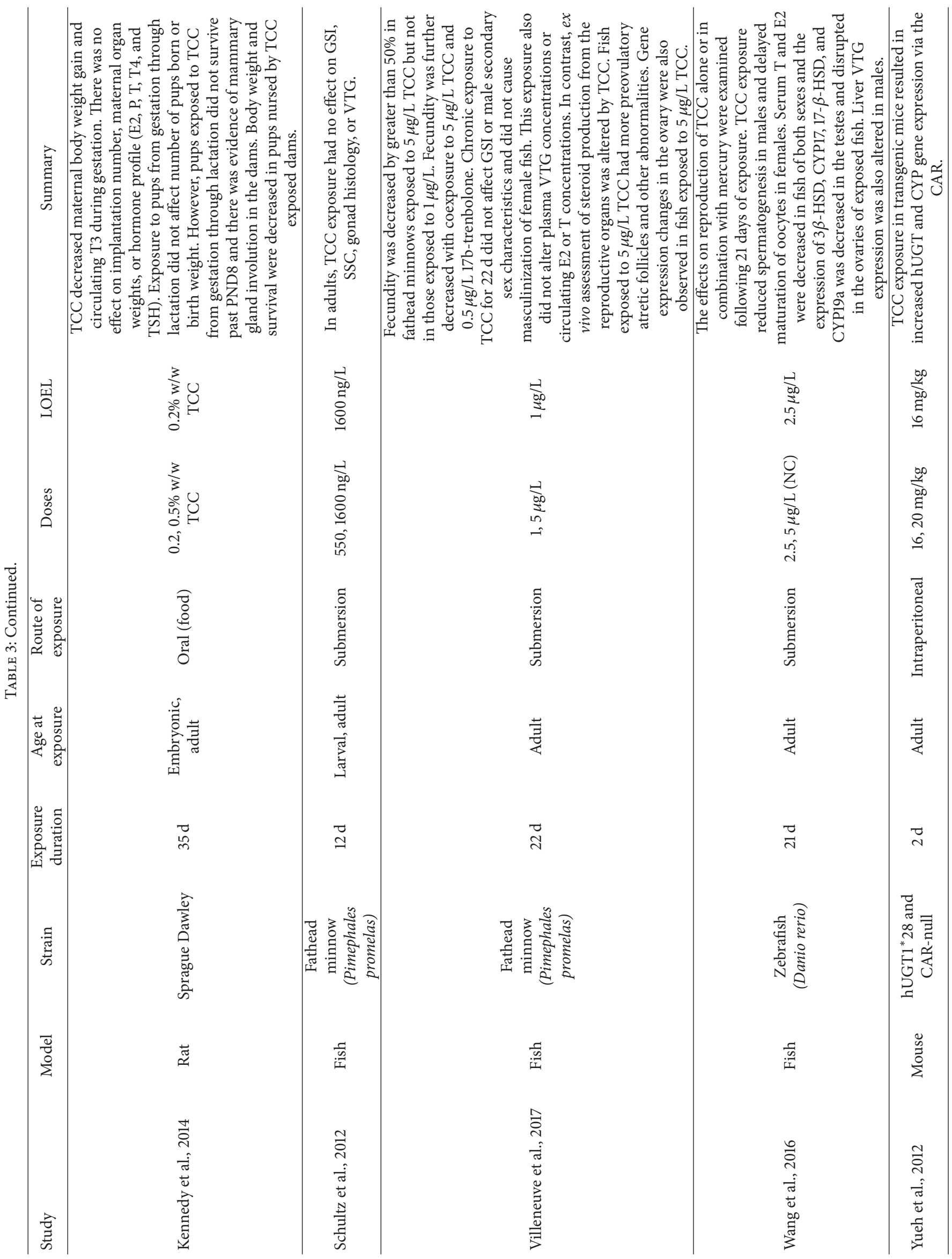




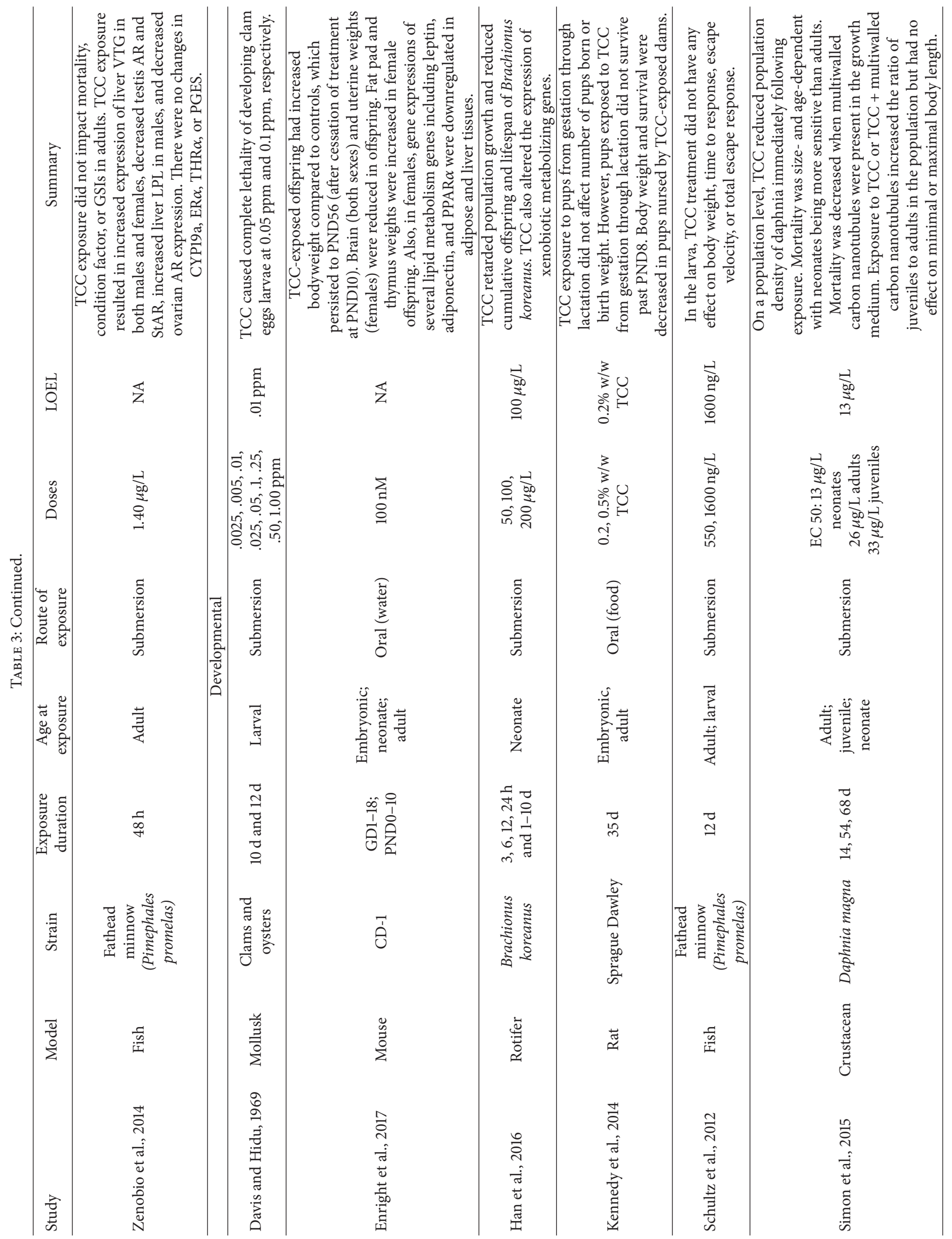




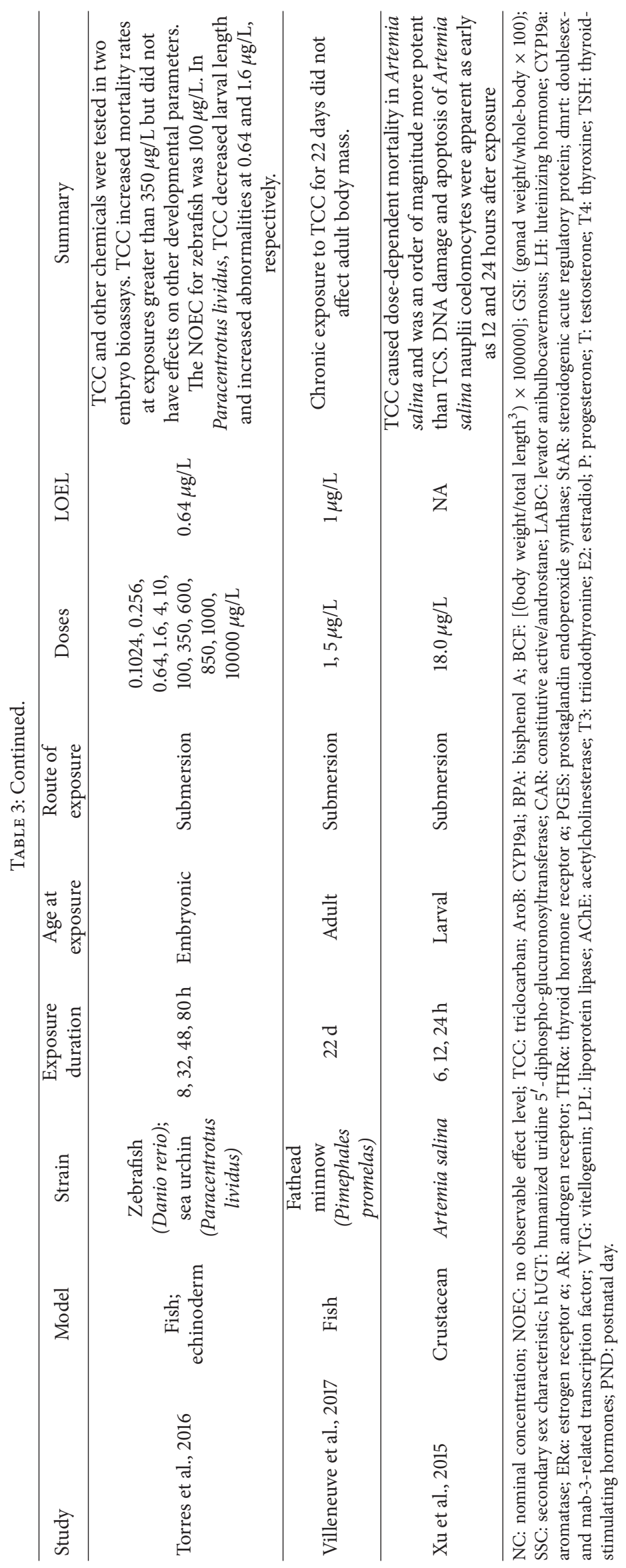




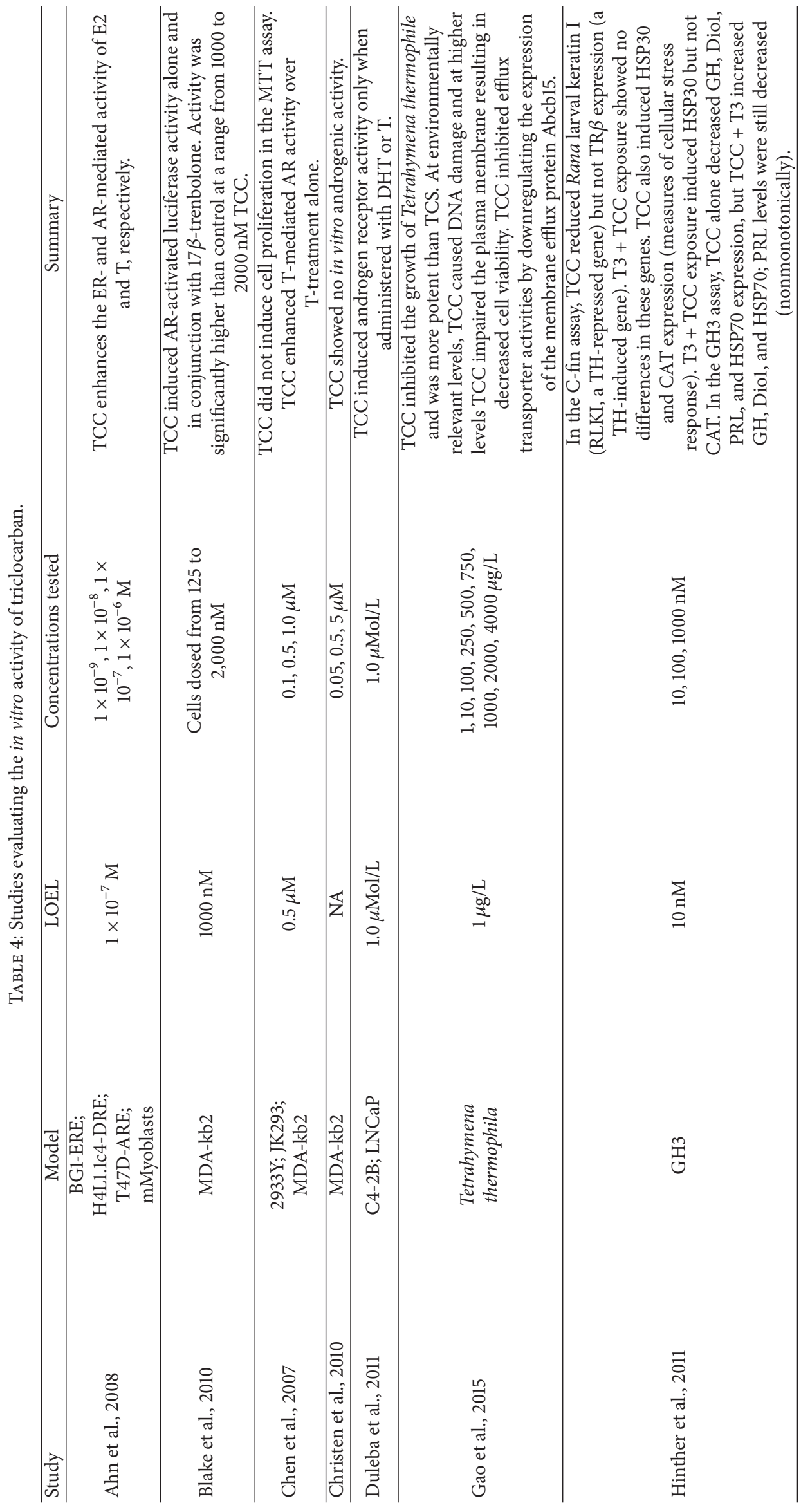




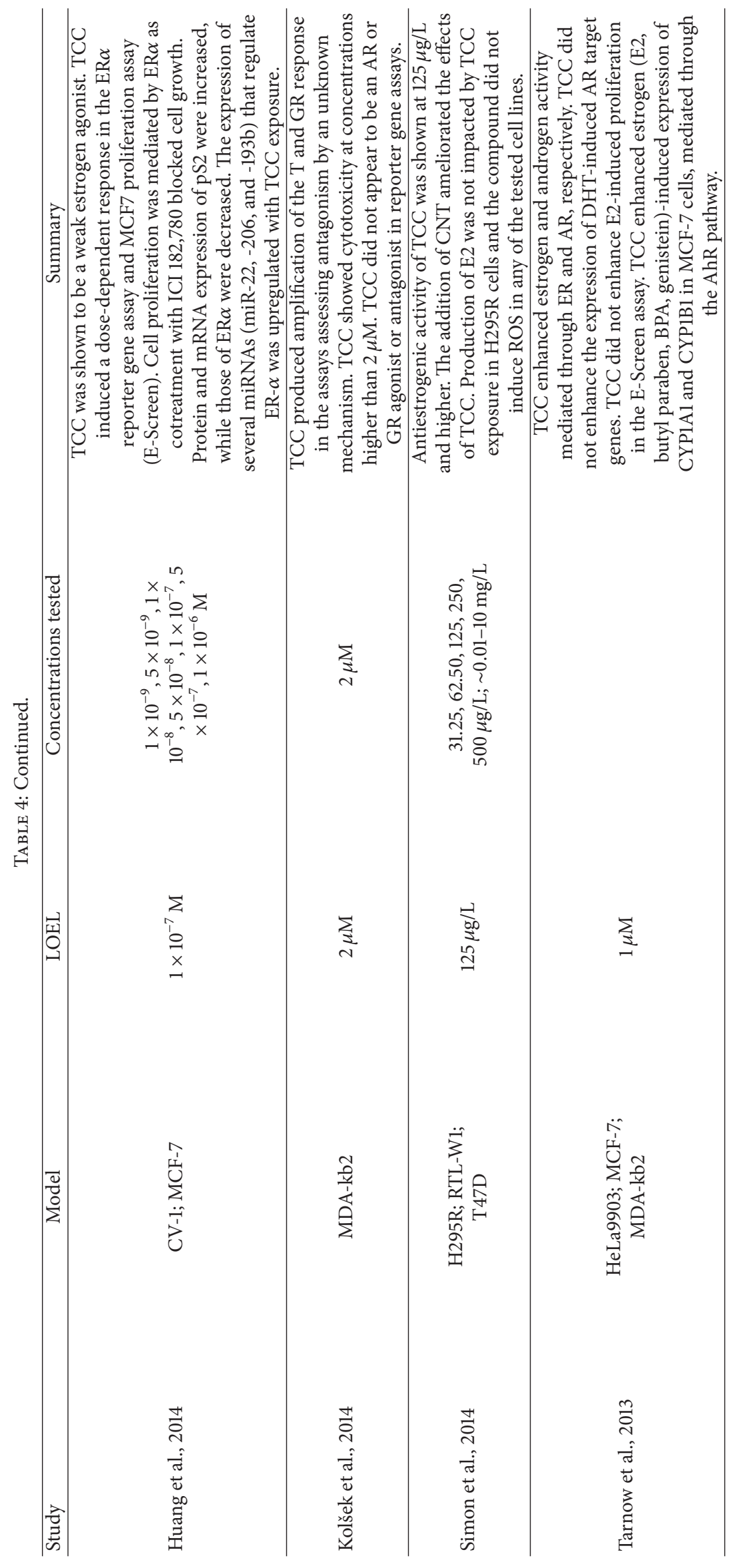




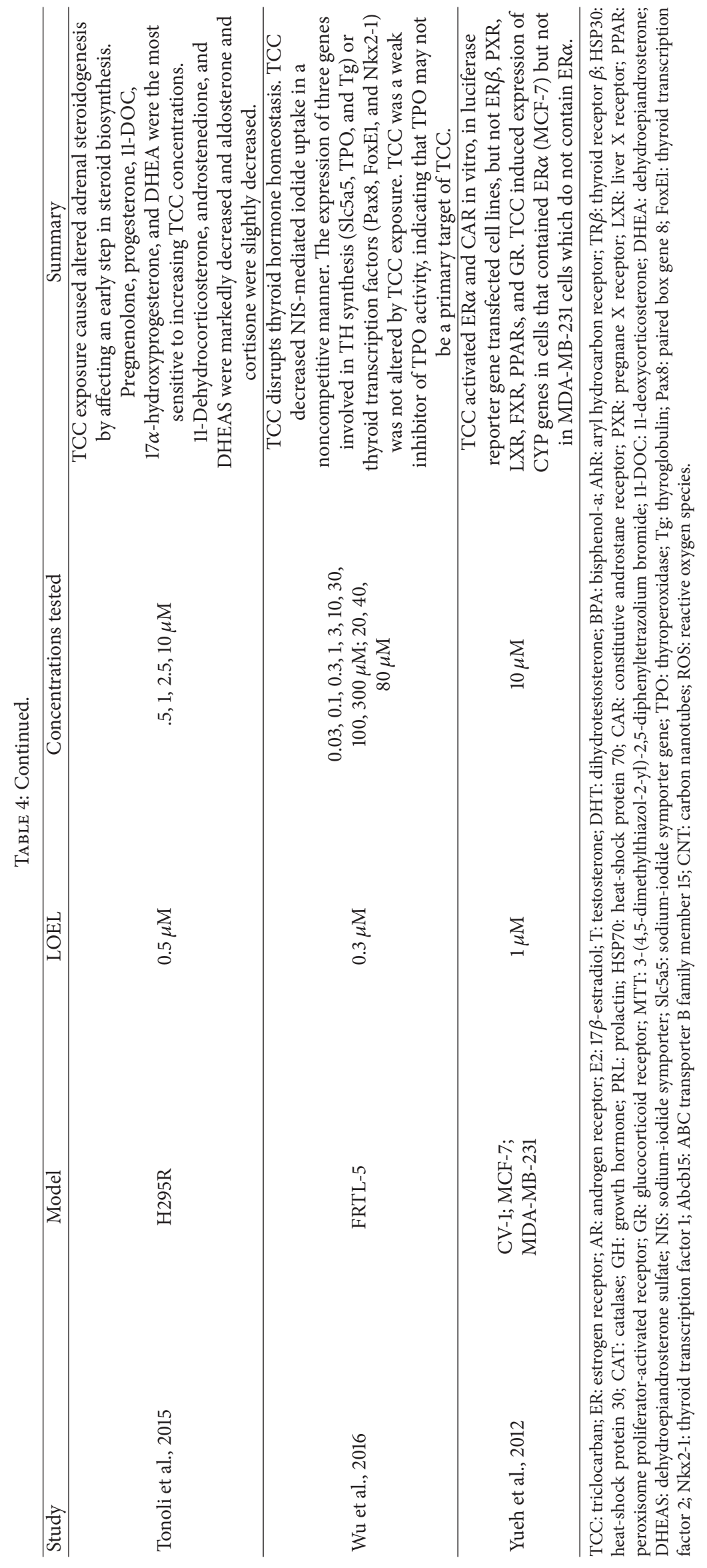


TABLE 5: Types of hormone systems assessed in vitro.

\begin{tabular}{|c|c|c|c|c|c|}
\hline Study & $\mathrm{E}$ & A & $\mathrm{T}$ & $\mathrm{G}$ & $\mathrm{P}$ \\
\hline Ahn et al., 2008 & $\checkmark$ & $\checkmark$ & & & \\
\hline Blake et al., 2010 & & $\checkmark$ & & & \\
\hline Chen et al., 2007 & & $\checkmark$ & & & \\
\hline Christen et al., 2010 & & $\checkmark$ & & & \\
\hline Duleba et al., 2011 & & $\checkmark$ & & & \\
\hline \multicolumn{6}{|l|}{ Gao et al., 2015} \\
\hline Hinther et al., 2011 & & & $\checkmark$ & & \\
\hline Huang et al., 2014 & $\checkmark$ & & & & \\
\hline Kolšek et al., 2014 & & $\checkmark$ & & $\checkmark$ & \\
\hline Simon et al., 2014 & $\checkmark$ & & & & \\
\hline Tarnow et al., 2013 & $\checkmark$ & $\checkmark$ & & & \\
\hline Tonoli et al., 2015 & & & & $\checkmark$ & $\checkmark$ \\
\hline Wu et al., 2016 & & & $\checkmark$ & & \\
\hline Yueh et al., 2012 & $\checkmark$ & & & $\checkmark$ & \\
\hline
\end{tabular}

E: estrogenic; A: androgenic; T: thyroidogenic; G: glucocorticodogenic; P: progestrogenic.

TABLE 6: Description of recommended systematic review endpoints.

\begin{tabular}{|c|c|c|c|}
\hline \multirow{2}{*}{ Number of studies } & \multicolumn{3}{|c|}{ Endpoint } \\
\hline & Estrogenic activity & Androgenic activity & Offspring growth \\
\hline Human & 0 & 0 & 1 \\
\hline Rodent & 1 & 2 & 2 \\
\hline Fish & 6 & 5 & 3 \\
\hline Invertebrates & 2 & 0 & 1 \\
\hline In vitro & 5 & 7 & $2^{* *}$ \\
\hline Total $^{*}$ & 14 & 14 & 9 \\
\hline \multicolumn{4}{|l|}{ Dose range } \\
\hline Human (detected) & NA & NA & $\begin{array}{c}0.13 \mu \mathrm{g} / \mathrm{L} \text { (cord blood plasma); } \\
3.44 \mu \mathrm{g} / \mathrm{g} \text { creatinine (urine) }\end{array}$ \\
\hline Rodent & $0.2-0.5 \% \mathrm{w} / \mathrm{w}$ & $0.25 \% \mathrm{w} / \mathrm{w}$ & $100 \mathrm{mM}, 0.2-0.5 \% \mathrm{w} / \mathrm{w}$ TCC \\
\hline Aquatic & $0.045-14.0 \mu \mathrm{g} / \mathrm{L}$ & $0.55-10 \mu \mathrm{g} / \mathrm{L}$ & $0.1-10000 \mu \mathrm{g} / \mathrm{L}$ \\
\hline In vitro & $1 \times 10^{-9}-1 \times 10^{-3} \mathrm{M}$ & $1 \times 10^{-9}-2 \times 10^{-3} \mathrm{M}$ & $3 \times 10^{-6}-3 \times 10^{-2} \mathrm{M}$ \\
\hline
\end{tabular}

TABLE 7: Research gaps of the effects of TCC on reproductive, endocrine, and developmental endpoints.

\begin{tabular}{lccc}
\hline & Reproductive & Endocrine & Developmental \\
\hline Human & - & - & + \\
Animal: mammals & + & + & + \\
Animal: nonmammals & + & +++ & ++ \\
In vitro & - & +++ & + \\
\hline$-:$ no research available; +: & some research (1-2 studies); & ++ : moderate \\
research (3-4 studies); +++: most research (5+ studies).
\end{tabular}

the current literature, using a framework such as the OHAT Systematic Review Framework [50] or the Navigation Guide $[69,70]$. The best candidate endpoints are the estrogenic and/or androgenic effects and offspring birth weight/growth. However, future research could add to the body of literature of each of these endpoints and improve the confidence of the results of any systematic reviews carried out. In particular, there are very few mammalian studies and almost no human studies. Thus, future research should include animal and human developmental growth studies and mammalian studies that include sensitive endocrine/reproductive endpoints. Systematic reviews of these topics, especially with the goal of deriving human health hazard conclusions of TCC effects, could aid in future research and regulation in order to most effectively protect human health.

\section{Conflicts of Interest}

The authors declare that there are no conflicts of interest regarding the publication of this paper.

\section{Acknowledgments}

Funding for this work was provided by the Arkansas Community Foundation, Winslow Foundation, Cornell Douglas 
Foundation, Wallace Genetic Foundation, and the International Chemical Secretariat (ChemSec). The authors would like to thank Christina Ribbens for help in literature procurement and cataloguing.

\section{References}

[1] R. J. Lewis, Hawley's Condensed Chemical Dictionary, John Wiley \& Sons, Inc, New York, NY, USA, 15th edition, 2007.

[2] Environmental Protection Agency Office of Pollution Prevention and Toxics. High Production Volume (HPV) Chemical Challenge Program Data Availability and Screening Level Assessment for Triclocarban (101-20-2) http://wwwepagov/ hpv/pubs/summaries/viewsrchhtm, 2012.

[3] R. J. Witorsch and J. A. Thomas, "Personal care products and endocrine disruption: a critical review of the literature," Critical Reviews in Toxicology, vol. 40, supplement 3, pp. 1-30, 2010.

[4] R. U. Halden and D. H. Paull, "Co-occurrence of triclocarban and triclosan in U.S. water resources," Environmental Science \& Technology, vol. 39, no. 6, pp. 1420-1426, 2005.

[5] X. Ye, L. Wong, P. Dwivedi, X. Zhou, T. Jia, and A. M. Calafat, "Urinary concentrations of the antibacterial agent triclocarban in united states residents: 2013-2014 national health and nutrition examination survey," Environmental Science \& Technology, vol. 50, no. 24, pp. 13548-13554, 2016.

[6] B. F. G. Pycke, L. A. Geer, M. Dalloul, O. Abulafia, A. M. Jenck, and R. U. Halden, "Human fetal exposure to triclosan and triclocarban in an urban population from Brooklyn, New York," Environmental Science \& Technology, vol. 48, no. 15, pp. 8831-8838, 2014.

[7] X. Zhou, X. Ye, and A. M. Calafat, "Automated on-line columnswitching HPLC-MS/MS method for the quantification of triclocarban and its oxidative metabolites in human urine and serum," Journal of Chromatography B, vol. 881-882, pp. 27-33, 2012.

[8] D. A. Haines, G. Saravanabhavan, K. Werry, and C. Khoury, "An overview of human biomonitoring of environmental chemicals in the Canadian Health Measures Survey: 2007-2019," International Journal of Hygiene and Environmental Health, vol. 220, no. 2, pp. 13-28, 2017.

[9] T. E. Arbuckle, L. Weiss, M. Fisher et al., "Maternal and infant exposure to environmental phenols as measured in multiple biological matrices," Science of the Total Environment, vol. 508, pp. 575-584, 2015.

[10] A. G. Asimakopoulos, N. S. Thomaidis, and K. Kannan, "Widespread occurrence of bisphenol A diglycidyl ethers, phydroxybenzoic acid esters (parabens), benzophenone typeUV filters, triclosan, and triclocarban in human urine from Athens, Greece," Science of the Total Environment, vol. 470-471, pp. 1243-1249, 2014.

[11] H. Frederiksen, J. K. Nielsen, T. A. Mørck et al., "Urinary excretion of phthalate metabolites, phenols and parabens in rural and urban Danish mother-child pairs," International Journal of Hygiene and Environmental Health, vol. 216, no. 6, pp. 772-783, 2013.

[12] K. T. de Renzy-Martin, H. Frederiksen, J. S. Christensen et al., "Current exposure of 200 pregnant Danish women to phthalates, parabens and phenols," Reproduction, vol. 147, no. 4, pp. 443-453, 2014.

[13] H. Frederiksen, T. K. Jensen, N. Jørgensen et al., "Human urinary excretion of non-persistent environmental chemicals: an overview of Danish data collected between 2006 and 2012," Reproduction, vol. 147, no. 4, pp. 555-565, 2014.

[14] J. Yin, L. Wei, Y. Shi, J. Zhang, Q. Wu, and B. Shao, "Chinese population exposure to triclosan and triclocarban as measured via human urine and nails," Environmental Geochemistry and Health, vol. 38, no. 5, pp. 1125-1135, 2016.

[15] H. Enright, V. Lao, M. S. Falso et al., “Transfer of triclocarban from mother to offspring during periods of development," Tech. Rep. LLNL-TR-663719, Lawrence Livermore National Laboratory (LLNL), Livermore, Calif, USA, 2014.

[16] H. A. Enright, M. J. Falso, M. A. Malfatti et al., "Maternal exposure to an environmentally relevant dose of triclocarban results in perinatal exposure and potential alterations in offspring development in the mouse model," PLoS ONE, vol. 12, no. 8, p. e0181996, 2017.

[17] J. M. Brausch and G. M. Rand, "A review of personal care products in the aquatic environment: Environmental concentrations and toxicity," Chemosphere, vol. 82, no. 11, pp. 1518-1532, 2011.

[18] M. A. Coogan and T. W. La Point, "Snail bioaccumulation of triclocarban, triclosan, and methyltriclosan in a North Texas, USA, stream affected by wastewater treatment plant runoff," Environmental Toxicology and Chemistry, vol. 27, no. 8, pp. 1788-1793, 2008.

[19] N. H. Schebb, I. Flores, T. Kurobe et al., "Bioconcentration, metabolism and excretion of triclocarban in larval Qurt medaka (Oryzias latipes)," Aquatic Toxicology, vol.105, no. 3-4, pp. 448454, 2011.

[20] N. H. Schebb, B. Franze, R. Maul, A. Ranganathan, and B. D. Hammock, "In Vitro Glucuronidation of the Antibacterial Triclocarban and Its Oxidative Metabolites," Drug Metabolism and Disposition, vol. 40, no. 1, pp. 25-31, 2011.

[21] R. A. Hiles and C. G. Birch, "The absorption, excretion, and biotransformation of 3,4,4'-trichlorocarbanilide in humans," Drug Metabolism and Disposition, vol. 6, no. 2, pp. 177-183, 1978.

[22] J. T. Warren, R. Allen, and D. E. Carter, "Identification of the metabolites of trichlorocarbanilide in the rat," Drug Metabolism and Disposition, vol. 6, no. 1, pp. 38-44, 1978.

[23] R. A. Hiles, D. Caudill, C. G. Birch, and T. Eichhold, "The metabolism and disposition of 3,4,4/-trichlorocarbanilide in the intact and bile duct-cannulated adult and in the newborn rhesus monkey (M. mulatta)," Toxicology and Applied Pharmacology, vol. 46, no. 3, pp. 593-608, 1978.

[24] R. A. Hiles and C. G. Birch, "Nonlinear metabolism and disposition of 3,4,4I-trichlorocarbanilide in the rat," Toxicology and Applied Pharmacology, vol. 46, no. 2, pp. 323-337, 1978.

[25] H. I. Maibach, L. G. Scharpf, and I. D. Hill, "Percutaneous penetration and disposition of triclocarban in man: Body showering," Archives of Environmental \& Occupational Health, vol. 30, no. 1, pp. 7-14, 1975.

[26] Food Drug Adminnistration HHS, "Safety and effectiveness of consumer antiseptics; topical antimicrobial drug products for over-the-counter human use," Federal Register, vol. 81, no. 172, pp. 61106-61130, 2016.

[27] J. Chen, K. C. Ahn, N. A. Gee et al., "Triclocarban enhances testosterone action: a new type of endocrine disruptor?" Endocrinology, vol. 149, no. 3, pp. 1173-1179, 2008.

[28] R. C. Kennedy, R. R. Fling, M. S. Robeson et al., "Temporal development of gut microbiota in triclocarban exposed pregnant and neonatal rats," Scientific Reports, vol. 6, article 33430, no. $1,2016$. 
[29] J. V. Ribado, C. Ley, T. D. Haggerty, E. Tkachenko, A. S. Bhatt, and J. Parsonnet, "Household triclosan and triclocarban exposure impacts the adult intestinal microbiome but not the infant intestinal microbiome," bioRxiv, vol. article 126334, 2017.

[30] K. J. Pflughoeft and J. Versalovic, "Human microbiome in health and disease," Annual Review of Pathology: Mechanisms of Disease, vol. 7, no. 1, pp. 99-122, 2012.

[31] L. Wei, P. Qiao, Y. Shi et al., "Triclosan/triclocarban levels in maternal and umbilical blood samples and their association with fetal malformation," Clinica Chimica Acta, vol. 466, pp. 133-137, 2017.

[32] L. A. Geer, B. F. G. Pycke, J. Waxenbaum, D. M. Sherer, O. Abulafia, and R. U. Halden, "Association of birth outcomes with fetal exposure to parabens, triclosan and triclocarban in an immigrant population in Brooklyn, New York," Journal of Hazardous Materials, vol. 323, pp. 177-183, 2017.

[33] R. C. Kennedy, F. Menn, L. Healy et al., "Early life triclocarban exposure during lactation affects neonate rat survival," Reproductive Sciences, vol. 22, no. 1, pp. 75-89, 2014.

[34] J. Han, E.-J. Won, U.-K. Hwang, I.-C. Kim, J. H. Yim, and J.-S. Lee, "Triclosan (TCS) and Triclocarban (TCC) cause lifespan reduction and reproductive impairment through oxidative stress-mediated expression of the defensome in the monogonont rotifer (Brachionus koreanus)," Comparative Biochemistry and Physiology Part - C: Toxicology and Pharmacology, vol. 185-186, pp. 131-137, 2016.

[35] A. Simon, T. G. Preuss, A. Schäffer, H. Hollert, and H. M. Maes, "Population level effects of multiwalled carbon nanotubes in Daphnia magna exposed to pulses of triclocarban," Ecotoxicology, vol. 24, no. 6, pp. 1199-1212, 2015.

[36] X. Xu, Y. Lu, D. Zhang et al., "Toxic assessment of triclosan and triclocarban on artemia salina," Bulletin of Environmental Contamination and Toxicology, vol. 95, no. 6, pp. 728-733, 2015.

[37] T. Torres, I. Cunha, R. Martins, and M. Santos, "Screening the Toxicity of Selected Personal Care Products Using Embryo Bioassays: 4-MBC, Propylparaben and Triclocarban," International Journal of Molecular Sciences, vol. 17, no. 10, p. 1762, 2016.

[38] H. Davis and H. Hidu, "Effects of pesticides on embryonic development of clams and oysters and on survival and growth of the larvae," Fishery Bulletin, vol. 67, no. 2, pp. 393-404, 1969.

[39] M. M. Schultz, S. E. Bartell, and H. L. Schoenfuss, "Effects of triclosan and triclocarban, two ubiquitous environmental contaminants, on anatomy, physiology, and behavior of the fathead minnow (Pimephales promelas)," Archives of Environmental Contamination and Toxicology, vol. 63, no. 1, pp. 114-124, 2012.

[40] D. L. Villeneuve, K. M. Jensen, J. E. Cavallin et al., "Effects of the antimicrobial contaminant triclocarban, and co-exposure with the androgen $17 \beta$-trenbolone, on reproductive function and ovarian transcriptome of the fathead minnow (Pimephales promelas)," Environmental Toxicology and Chemistry, vol. 36, no. 1, pp. 231-242, 2017.

[41] A. J. Duleba, M. I. Ahmed, M. Sun et al., "Effects of Triclocarban on Intact Immature Male Rat," Reproductive Sciences, vol. 18, no. 2, pp. 119-127, 2011.

[42] M. Yueh, T. Li, R. M. Evans, B. Hammock, R. H. Tukey, and V. D. Appanna, "Triclocarban mediates induction of xenobiotic metabolism through activation of the constitutive androstane receptor and the estrogen receptor alpha," PLoS ONE, vol. 7, article e37705, no. 6, 2012.

[43] S. Barros, R. Montes, J. B. Quintana et al., "Chronic effects of triclocarban in the amphipod Gammarus locusta: Behavioural and biochemical impairment," Ecotoxicology and Environmental Safety, vol. 135, pp. 276-283, 2017.

[44] C. Geiss, K. Ruppert, T. Heidelbach, and J. Oehlmann, “The antimicrobial agents triclocarban and triclosan as potent modulators of reproduction in Potamopyrgus antipodarum (Mollusca: Hydrobiidae)," Journal of Environmental Science and Health, Part A: Toxic/Hazardous Substances and Environmental Engineering, vol. 51, no. 13, pp. 1173-1179, 2016.

[45] B. D. Giudice and T. M. Young, "The antimicrobial triclocarban stimulates embryo production in the freshwater mudsnail Potamopyrgus antipodarum," Environmental Toxicology and Chemistry, vol. 29, no. 4, pp. 966-970, 2010.

[46] G. T. Ankley, K. M. Jensen, M. D. Kahl et al., "Use of chemical mixtures to differentiate mechanisms of endocrine action in a small fish model," Aquatic Toxicology, vol. 99, no. 3, pp. 389396, 2010.

[47] E. Chung, M. C. Genco, L. Megrelis, and J. V. Ruderman, "Effects of bisphenol A and triclocarban on brain-specific expression of aromatase in early zebrafish embryos," Proceedings of the National Acadamy of Sciences of the United States of America, vol. 108, no. 43, pp. 17732-17737, 2011.

[48] P. Wang, Z. Du, S. Gao, X. Zhang, and J. P. Giesy, "Impairment of reproduction of adult zebrafish (Danio rerio) by binary mixtures of environmentally relevant concentrations of triclocarban and inorganic mercury," Ecotoxicology and Environmental Safety, vol. 134, pp. 124-132, 2016.

[49] J. E. Zenobio, B. C. Sanchez, L. C. Archuleta, and M. S. Sepulveda, "Effects of triclocarban, N,N-diethyl-meta-toluamide, and a mixture of pharmaceuticals and personal care products on fathead minnows (Pimephales promelas)," Environmental Toxicology and Chemistry, vol. 33, no. 4, pp. 910-919, 2014.

[50] National Toxicology Program. Handbook for Conducting a Literature-Based Health Assessment Using OHAT Approach for Systematic Review and Evidence Integration. Office of Health Assessment and Translation (OHAT), Division of the National Toxicology Program, National Institute of Environmental Health Sciences https://ntpniehsnihgov/ntp/ohat/pubs/ handbookjan2015_508pdf., 2015.

[51] K. C. Ahn, B. Zhao, J. Chen et al., "In vitro biologic activities of the antimicrobials triclocarban, its analogs, and triclosan in bioassay screens: Receptor-based bioassay screens," Environmental Health Perspectives, vol. 116, no. 9, pp. 1203-1210, 2008.

[52] L. S. Blake, D. Martinović, L. E. Gray et al., "Characterization of the androgen-sensitive MDA-kb2 cell line for assessing complex environmental mixtures," Environmental Toxicology and Chemistry, vol. 29, no. 6, pp. 1367-1376, 2010.

[53] V. Christen, P. Crettaz, A. Oberli-Schrämmli, and K. Fent, "Some flame retardants and the antimicrobials triclosan and triclocarban enhance the androgenic activity in vitro," Chemosphere, vol. 81, no. 10, pp. 1245-1252, 2010.

[54] L. Gao, T. Yuan, P. Cheng et al., "Effects of triclosan and triclocarban on the growth inhibition, cell viability, genotoxicity and multixenobiotic resistance responses of Tetrahymena thermophila," Chemosphere, vol. 139, pp. 434-440, 2015.

[55] A. Hinther, C. M. Bromba, J. E. Wulff, and C. C. Helbing, "Effects of triclocarban, triclosan, and methyl triclosan on thyroid hormone action and stress in frog and mammalian culture systems," Environmental Science \& Technology, vol. 45, no. 12, pp. 5395-5402, 2011.

[56] H. Huang, G. Du, W. Zhang, J. Hu, D. Wu, L. Song et al., "The in vitro estrogenic activities of triclosan and triclocarban," Journal of Applied Toxicology, vol. 34, no. 9, pp. 1060-1067, 2014. 
[57] K. Kolšek, M. Gobec, I. Mlinarič Raščan, and M. Sollner Dolenc, "Screening of bisphenol A, triclosan and paraben analogues as modulators of the glucocorticoid and androgen receptor activities," Toxicology in Vitro, vol. 29, no. 1, pp. 8-15, 2014.

[58] A. Simon, S. X. Maletz, H. Hollert, A. Schäffer, and H. M. Maes, "Effects of multiwalled carbon nanotubes and triclocarban on several eukaryotic cell lines: Elucidating cytotoxicity, endocrine disruption, and reactive oxygen species generation," Nanoscale Research Letters, vol. 9, no. 1, pp. 1-15, 2014.

[59] P. Tarnow, T. Tralau, D. Hunecke, and A. Luch, "Effects of triclocarban on the transcription of estrogen, androgen and aryl hydrocarbon receptor responsive genes in human breast cancer cells," Toxicology in Vitro, vol. 27, no. 5, pp. 1467-1475, 2013.

[60] D. Tonoli, C. Fürstenberger, J. Boccard et al., "Steroidomic Footprinting Based on Ultra-High Performance Liquid Chromatography Coupled with Qualitative and Quantitative HighResolution Mass Spectrometry for the Evaluation of Endocrine Disrupting Chemicals in H295R Cells," Chemical Research in Toxicology, vol. 28, no. 5, pp. 955-966, 2015.

[61] Y. Wu, F. A. Beland, and J.-L. Fang, "Effect of triclosan, triclocarban, 2,2',4,4'-tetrabromodiphenyl ether, and bisphenol A on the iodide uptake, thyroid peroxidase activity, and expression of genes involved in thyroid hormone synthesis," Toxicology in Vitro, vol. 32, pp. 310-319, 2016.

[62] H. Arksey and L. O’Malley, "Scoping studies: towards a methodological framework," International Journal of Social Research Methodology, vol. 8, no. 1, pp. 19-32, 2005.

[63] H. L. Colquhoun, D. Levac, K. K. O’Brien et al., "Scoping reviews: Time for clarity in definition, methods, and reporting," Journal of Clinical Epidemiology, vol. 67, no. 12, pp. 1291-1294, 2014.

[64] D. Levac, H. Colquhoun, and K. K. O’Brien, "Scoping studies: advancing the methodology," Implementation Science, vol. 5, no. 69, 2010.

[65] A. L. Bolden, J. R. Rochester, and C. F. Kwiatkowski, "Melamine, beyond the kidney: A ubiquitous endocrine disruptor and neurotoxicant?" Toxicology Letters, vol. 280, pp. 181-189, 2017.

[66] A. L. Bolden, J. R. Rochester, K. Schultz, and C. F. Kwiatkowski, "Polycyclic aromatic hydrocarbons and female reproductive health: A scoping review," Reproductive Toxicology, vol. 73, pp. 61-74, 2017.

[67] P. I. Johnson, P. Sutton, E. Koustas, H. M. Vesterinen, and T. J. Woodruff, "Application of the Navigation Guide systematic review methodology to the evidence for developmental and reproductive toxicity of triclosan," Environment International, vol. 92-93, pp. 716-728, 2016.

[68] P. I. Johnson, P. Sutton, D. S. Atchley et al., "The navigation guide-evidence-based medicine meets environmental health: systematic review of human evidence for pfoa effects on fetal growth," Environmental Health Perspectives, vol. 122, no. 10, pp. 1028-1039, 2014.

[69] E. Koustas, J. Lam, P. Sutton et al., "The navigation guideevidence-based medicine meets environmental health: systematic review of nonhuman evidence for pfoa effects on fetal growth," Environmental Health Perspectives, vol. 122, no. 10, pp. 1015-1027, 2014.

[70] J. Lam, E. Koustas, P. Sutton et al., "The navigation guideevidence-based medicine meets environmental health: integration of animal and human evidence for pfoa effects on fetal growth," Environmental Health Perspectives, vol. 122, no. 10, pp. 1040-1051, 2014.
[71] B. D. Palmer and K. W. Selcer, "Vitellogenin as a biomarker for xenobiotic estrogens: A review. Environmental toxicology and risk assessment: biomarkers and risk assessment," ASTM International, vol. 5, 1996. 

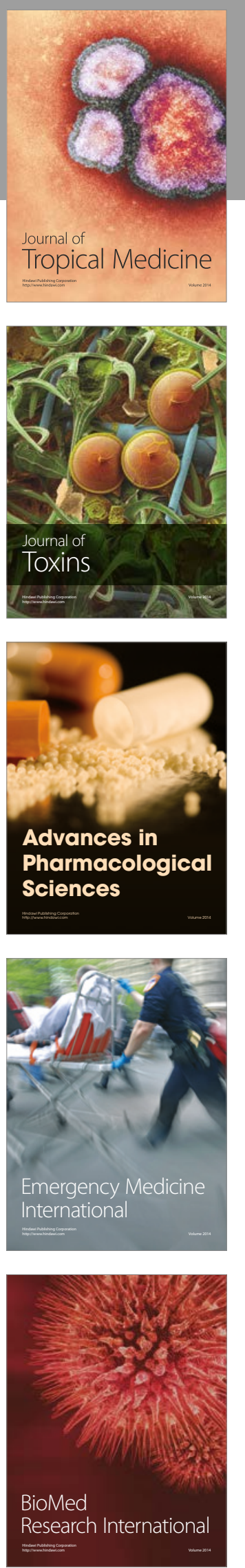


Submit your manuscripts at

https://www.hindawi.com
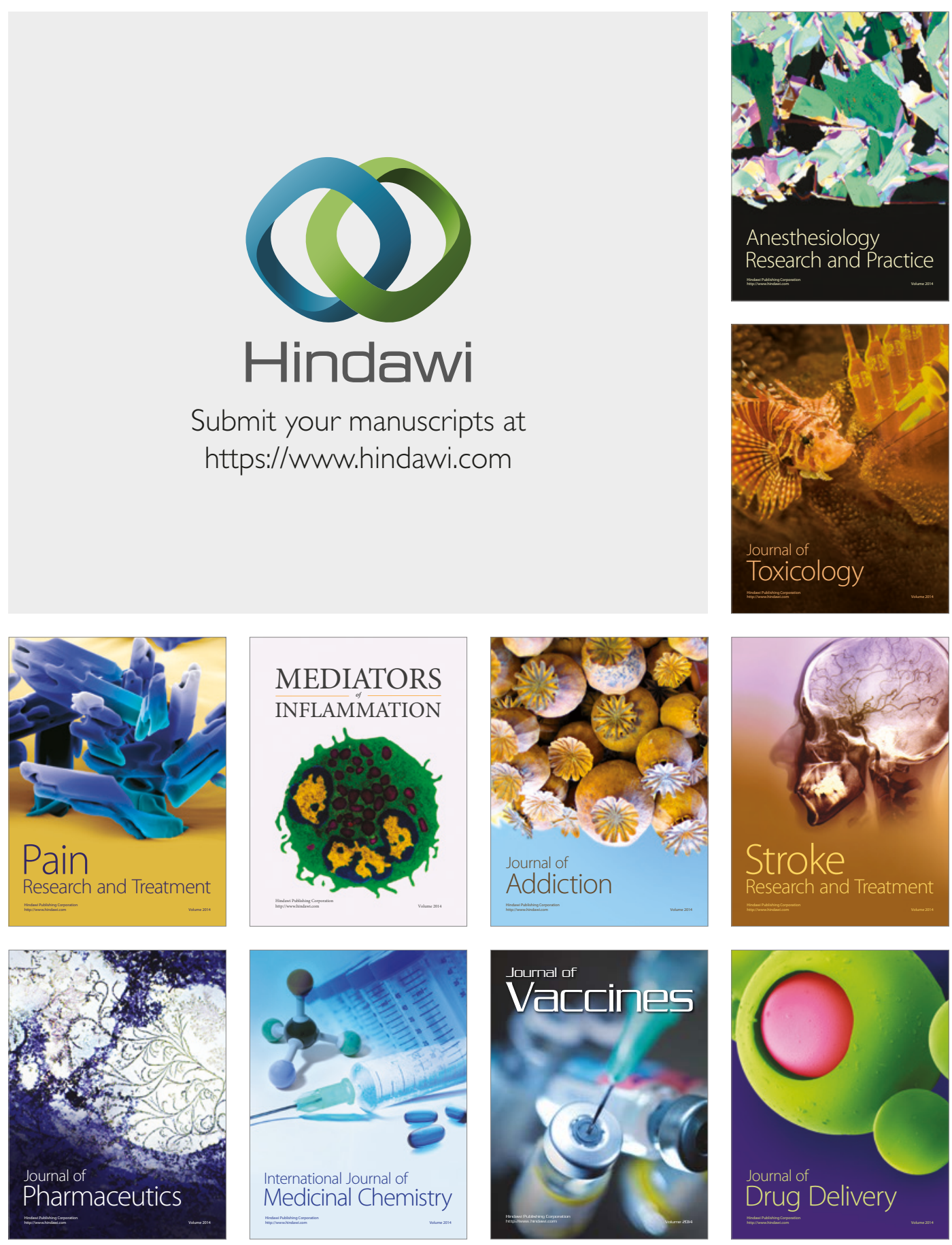